\title{
Study of Lophomonas blattarum Infection in Kidney Transplant Patients in Mashhad City, Iran
}

\author{
Zahra Gheisari $(\mathbb{D}),{ }^{1}$ Fariba Berenji $(\mathbb{D}),{ }^{1}$ Fatemeh Nazemian $\left(\mathbb{D}^{2}{ }^{2}\right.$ \\ Seyed Ali Akbar Shamsian (D), ${ }^{1}$ Lida Jarahi (D), ${ }^{3}$ Mahmoud Parian (D), \\ Bibi Razieh Hosseini Farash $\mathbb{D}^{1},{ }^{1}$ and Ghodratollah Salehi Sangani $\mathbb{D}^{1}$ \\ ${ }^{1}$ Department of Parasitology and Mycology, Faculty of Medicine, Mashhad University of Medical Sciences, Mashhad, Iran \\ ${ }^{2}$ Department of Nephrology, Emam Reza Hospital, Mashhad University of Medical Sciences, Mashhad, Iran \\ ${ }^{3}$ Department of Community Medicine, Faculty of Medicine, Mashhad University of Medical Sciences, Mashhad, Iran \\ ${ }^{4}$ Department of Parasitology and Mycology, Emam Reza Hospital, Mashhad University of Medical Sciences, Mashhad, Iran
}

Correspondence should be addressed to Fariba Berenji; fberenji@yahoo.com and Ghodratollah Salehi Sangani; salehigh1@gmail.com

Received 7 October 2020; Revised 29 November 2020; Accepted 4 December 2020; Published 17 December 2020

Academic Editor: Albert Eid

Copyright ( $\odot 2020$ Zahra Gheisari et al. This is an open access article distributed under the Creative Commons Attribution License, which permits unrestricted use, distribution, and reproduction in any medium, provided the original work is properly cited.

Background. Lophomonas blattarum is a flagellate protozoan which is known as an emerging parasite in the human respiratory system. Organ transplant recipients are considered as immunocompromised patients due to prescription of immunosuppressive drugs. This group of patients is susceptible to opportunistic infection as well as lophomoniasis. This study aims to investigate the prevalence and clinical manifestation of pulmonary infections caused by L. blattarum in kidney transplant recipients. Methods. This is a case-control study including 50 kidney transplant recipients and 50 controls. The sputum samples were collected from 50 kidney transplant recipients with bronchopulmonary infection signs suspected to lophomoniasis admitted in Montaserieh and Imam Reza hospitals, Mashhad, Iran. 50 healthy individuals as the control group were matched for sex and age with case ones. The consent form, checklist, and required information were provided for each patient. All samples were microscopically examined for the flagellated protozoan, L. blattarum, using direct smear. Results. Among 50 kidney transplant recipients suspected to lophomoniasis, L. blattarum was identified in sputum samples of 4 (8\%) participants of the case group including one female and three males. None of the samples were positive among the control group. Symptoms in patients of this study were high fever (4 out of 4 patients), cough ( 3 out of 4 patients), and dyspnea ( 2 out of 4 patients). Three patients showed a positive response to metronidazole treatment. Conclusion. The results of this study suggest that L. blattarum should be considered as a pathogenic agent in kidney transplant recipients. It is necessary to examine sputum samples in posttransplant pneumonia patients, especially in those resistant to antibacterial therapy.

\section{Introduction}

Infectious agents are one of the most common causes of mortality among kidney transplant recipients. Leismaniasis and malaria are the most common protozoan infections in the posttransplantation period [1]. Pulmonary infection in kidney transplant recipients is usually caused by respiratory viruses, CMV, bacterial and fungal pathogens, and Pneumocystis jirovecii [2]. Recently, pulmonary infection by Lophomonas as an emerging infection has been increasingly considered, especially in immunocompromised patients $[3,4]$. This parasite can infect immunocompetent individuals [5] and is more common in patients with immune deficiencies [6]. The first case of lophomoniasis was reported by Chen and Mengsin in 1993 [7]. The first case of lophomoniasis in Iran was reported in a 31-year-old woman with sinusitis by Fariba Berenji in 2015 [8]. After that, other studies were carried out to investigate prevalence and pathogenicity of $L$. blattarum at different ages among the patients with different clinical conditions such as allergic asthma $[9,10]$, sinusitis $[8,11]$, and coinfection with tuberculosis [12], immunocompetent and immunocompromised patients $[13,14]$, and pediatric patients 
$[15,16]$. Sobarzo reported a high prevalence of $35.8 \%$ in sputum samples of patients with respiratory disorders [17]. Also, L. blattarum was diagnosed in $33.8 \%$ of BAL samples by Berenji et al. [5].

Organ transplant recipients are more susceptible to infection because of the use of immunosuppressive drugs that result in mortality and morbidity after transplantation. Therefore, prevention, early diagnosis, and proper treatment of infectious diseases are vital factors in successful transplantation.

L. blattarum is usually round, oval pyriform with a length approximately from 20 to $60 \mu \mathrm{m}$ and a width from 12 to $20 \mu \mathrm{m}$. This parasite has a tuft of flagella in which longer ones in the center are surrounded by the smaller ones in the periphery and extend from the anterior pole of the organism. The current diagnostic method of this parasite is based on morphological characteristics in human fresh samples including sputum, bronchoalveolar lavages (BALs), and tracheal aspirates. This multiflagellated parasite may be confused with the ciliated bronchial cells in BAL samples under the light microscope. However, there are some morphological features to differentiate between the parasite and ciliated bronchial cells such as marked terminal bar and columnar shape of epithelial cells, difference in position of the nucleus, and identical length of cilia in epithelial cells versus unequal length of flagella in the parasite [18].

This work was conducted to study the prevalence and clinical manifestation of lophomoniasis in kidney transplant patients and to compare with healthy individuals. The results of this study can provide a new insight to L. blattarum as a potential agent for pulmonary infection in organ transplant recipients.

\section{Materials and Methods}

2.1. Ethical Consideration. The research proposal has been approved by the Ethics Committee of Mashhad University of Medical Sciences (ethical code no. IR.MUMS.fm.REC.1396.397) in accordance with Helsinki Declaration guidelines. The patients were taken under study after signing the consent forms. Authorizations for children's participation were given by their legal guardians.

2.2. Study Population. The sample size was determined based on prevalence and frequency of L. blattarum in a study done by Mirzazadeh et al. in Mashhad with 95\% confidence level with a margin of error of less than $10 \%$ [9].

2.3. Data Collection and Analysis. In this case-control study (Nov 2018-Nov 2019), after obtaining the consent form and questionnaire, including demographic data and clinical signs, sputum samples were collected from 50 kidney transplant recipients with pulmonary disorders admitted in Montaserieh and Imam Reza hospitals in Mashhad, Iran (case group) and 50 healthy individuals (control group) who were chosen from healthy members of patients' family. Taking into account the inclusion criteria, patients with a history of kidney transplantation, medicated with immunosuppressive drugs, and who were hospitalized for pulmonary disorders were considered to be in the case group. The use of antiparasitic drugs was considered as an exclusion criterion. The case and control groups were matched for age and sex.

A nebulizer device was used to facilitate sputum sampling for patients who had difficulty in producing sputum spontaneously. In this method, the patient inhales nebulized hypertonic saline solution, which liquefies airway secretions, promotes coughing, and allows expectoration of respiratory secretions. Sputum induction is simple and noninvasive, and if successful, often precludes the need for bronchoscopy. Sputum samples were examined using direct smear, Papanicolaou, and hematoxylin and eosin (H\&E) staining for the parasite (Figure 1). Statistical analysis was performed using SPSS software version 16 (SPSS Inc., Chicago, IL) using Student's $t$-test.

\section{Results}

A total of 100 participants were included in this study consisting of 50 kidney transplant recipients and 50 healthy controls. There is not a significant difference of age between patients and healthy control groups. Age average was $48.14 \pm 13.47$ and $47.74 \pm 13.27$ for the patient and control groups, respectively $(p$-value $=0.82)$. In the healthy control group, none of the sputum samples was positive for Lophomonas. In the patients group, $4(8 \%)$ cases were positive for Lophomonas including three males and one female with an age average of 58 years. The length of transplantation was 16.5 years for patients with lophomoniasis versus 14 years for patients without lophomoniasis. Diabetes and cancer were not reported for none of the patients with lophomoniasis. There was no coinfection with HIV in any patients. Also, none of the patients with lophomoniasis declared a history of smoking. The CMV test was positive for one patient. Also, candida was detected in BAL samples obtained from two patients. Among the patients infected with Lophomonas, fever, cough, and dyspnea were the main clinical symptoms and were seen in four, three, and two patients, respectively. Weight loss, night sweat, wheezing, and chest pain were not found in any patient infected with Lophomonas (Figure 2). Treatment with metronidazole was effective for two patients. One patient died before metronidazole therapy, and no data were available for the latter.

\section{Discussion}

In the current study, L. blattarum was detected in 4 (8\%) sputum samples of kidney transplant recipients with bronchopulmonary symptoms. Reported prevalence has been varying in different studies. A high prevalence of $40.4 \%$ has been reported in children with respiratory disorders during 2016-2017 in Mashhad, Iran [15]. Also, 33.8\% of BAL samples were positive for L. blattarum in a study published by Berenji et al. [5]. In another study by Mirzazadeh et al., the reported prevalence of the parasite was $10 \%$ among 40 asthmatic patients [9], which is almost in accordance with our study. Also, L. blattarum was diagnosed in 4 (2.8\%) of 


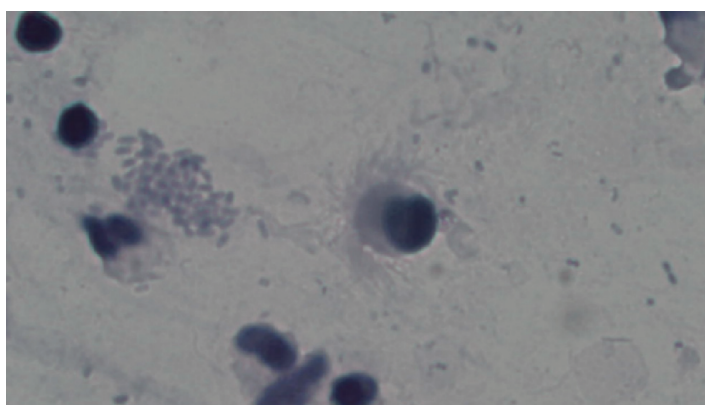

(a)

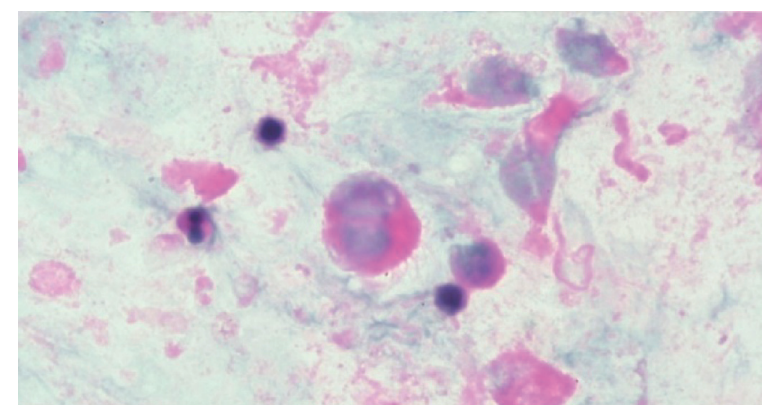

(b)

Figure 1: Trophozoite of L. blattarum with long flagella in a sputum sample: (a) H\&E and (b) Papanicolaou stain.

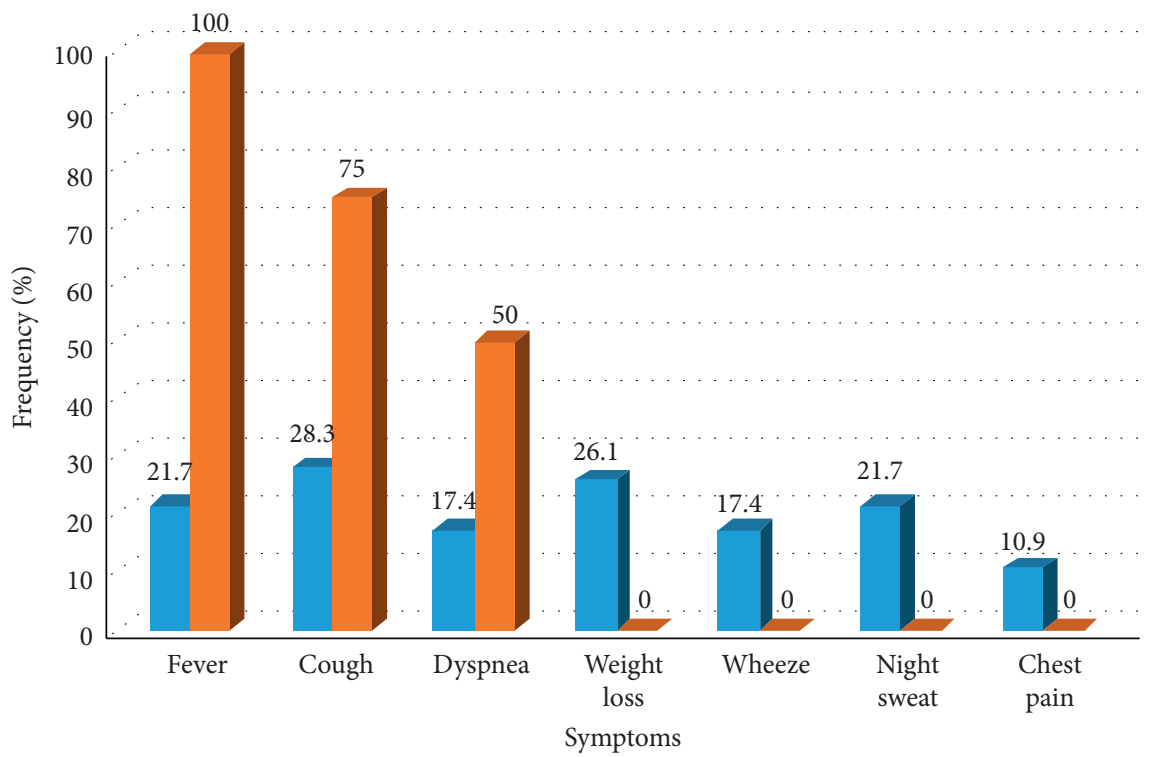

Lophomonas (-)

Lophomonas $(+)$

FIGURE 2: Comparison of clinical signs among patients of the case group with lophomoniasis and without lophomoniasis.

142 BAL samples of kidney transplant recipients by Wang et al. [1].

The results of published studies show that clinical signs of lophomoniasis are nonspecific [19]. According to our results, fever $(100 \%)$ and cough $(75 \%)$ were reported as common clinical symptoms in patients infected with L. blattarum similar to other studies conducted in Iran and China [20, 21]. Zhang et al. through a literature review from 1993 to 2010 reported that cough and fever were present, respectively, in $88.9 \%$ and $68.9 \%$ of patients with lophomoniasis [20]. Also, cough $(87.3 \%)$ and fever $(28.3 \%)$ were reported as the most common respiratory symptoms among children infected with L. blattarum in Mashhad, Iran [15]. In another study conducted in Mashhad, Iran, coughing and fever were mentioned as the most common symptoms [21]. Of course, fever was the second most common symptom in these studies, on the contrary of findings in the current study in which fever was the most reported symptom. In another study in the Institution of Nephrology in Jin Ling Hospital, China, high fever (higher than 38 o C) without cough and breathlessness was recorded in kidney transplant recipients with lophomoniasis during the second to third month after transplantation [1]. In this study, infection occurred during a short time after transplantation, while in our study, a long time has passed over from transplantation of the patients. The results of our study were in agreement with the Qiang He study in which fever has been reported in two patients with lophomoniasis who had kidney transplantation more than one year ago [22]. As the highest level of immunosuppression usually occurs during the first six months posttransplantation [23], opportunistic infections are common in this period. Infection with Lophomonas a long time after transplantation as well as in immunocompetent individuals $[8,9,15]$ implies considering that this organism is not just an opportunistic parasite.

Dyspnea was the third most common clinical symptom (50\%) in our study, which is consistent with other studies [21]. Unlike our study, dyspnea was absent among patients included in the Yang Wang study [1]. In this study, patients were in the initial period of disease and dyspnea is usually reported in the late period due to disease progression. 
Wheezing, one of the clinical symptoms in patients with lophomoniasis, was less reported in previous studies. In the current study, wheezing was not detected in any patient. Nevertheless, in another study conducted in Mashhad, Iran, it was reported as one of the four common clinical symptoms among children infected with $L$. blattarum [15]. Low prevalence of wheezing may be due to the age of the population under study. Wheezing is more common in children because of anatomical factors such as small caliber of airways and also some immunological factors that result in excessive amounts of secretions [24].

Other clinical symptoms such as weakness, weight loss, chest pain, night sweat, chill, and hemoptysis are less common symptoms reported in patients with lophomoniasis and are also not reported in our patients. Also, they are not present in our findings. Absence of these clinical symptoms may be partially helpful to differentiate lophomoniasis from other pulmonary infections. However, sputum samples from patients with lung infection should be examined for Lophomonas, especially if the patient's clinical manifestations have not disappeared after treatment for common lung infections.

L. blattarum with protease enzyme facilitates other respiratory infections such as TB and fungal and viral infection. Therefore, a mix infection of L. blattarum with other pathogens may be observed [5]. Two cases (50\%) and one case $(25 \%)$ of patients of our study had a mix infection with candida and CMV. These results are in accordance to the $\mathrm{He}$ et al. study that reported a fungal concomitant infection in a patient with lophomoniasis [22].

Metronidazole is the ideal choice drug and has been proved to be effective for treatment of $L$. blattarum infection as reported in previous studies [21, 25-27]. Similarly, patients in the current study were treated with metronidazole $500 \mathrm{mg}$ b.i.d. for 15 days, and clinical symptoms were gradually ameliorated.

\section{Conclusion}

A prevalence of $8 \%$ for L. blattarum symptomatic infection among kidney transplant recipients was reported in the current study. Taking into account the relatively high prevalence of cases of lophomoniasis in kidney transplant patients and the growing number of these transplant recipients, it is suggested that they be routinely screened for L. blattarum to reduce their morbidity and mortality.

\section{Data Availability}

The data used to support the findings of this study are included within the article.

\section{Conflicts of Interest}

The authors declare that they have no conflicts of interest.

\section{Acknowledgments}

This study was a part of the MSc student thesis and funded by Mashhad University of Medical Sciences, Mashhad, Iran. The authors appreciate the Vice-Chancellor for Research for financial support of this study.

\section{References}

[1] Y. Wang, Z. Tang, S. Ji et al., "Pulmonary Lophomonas blattarum infection in patients with kidney allograft transplantation," Transplant International, vol. 19, no. 12, pp. 1006-1013, 2006.

[2] P.-y Cheng, G.-q Zhang, G.-g Xie, X.-q Jin, and X. Zhou, "Symbol Different pathogens and prognostic factors of renal transplant recipients with lung infection in 46 cases," Journal of Clinical Rehabilitative Tissue Engineering Research, vol. 13, no. 5, pp. 931-934, 2009.

[3] S. Chen and Z. Meng, "Report on one case of Lophomonas blattarum in the respiratory tract," Chinese Journal of Parasitology and Parasitic Diseases, vol. 11, no. 11, p. 28, 1993.

[4] M. Bai, X. Yao, and Q. Li, "Report on one case of lung infection with hypermastigote," Chinese Journal of Internal Medicine, vol. 43, no. 43, pp. 868-869, 2004.

[5] F. Berenji, A. Fata, V. Vakili, S. J. Sayedi, B. Abdollahi, and H. Imanfar, "Unexpected high rate of Lophomonas blattarum in resistant upper and lower respiratory infection," Health Sciences, vol. 5, no. 9, pp. 74-80, 2016.

[6] A. Ribas, R. Martínez-Girón, J. Sánchez-Del-Río, and D. González-Alonso, "Protozoal forms in the sputum of immunocompromized patients," Scandinavian Journal of Infectious Diseases, vol. 37, no. 3, pp. 205-210, 2005.

[7] S. Chen and Z. Meng, "Bronchopulmonary Lophomonas blattarum infection: a case report," Chinese Journal of Parasitology and Parasitic Diseases, vol. 11, p. 28, 1993.

[8] F. Berenji, M. Parian, A. Fata, M. Bakhshaee, and F. Fattahi, "First case report of sinusitis with Lophomonas blattarum from Iran," Case Reports in Infectious Diseases, vol. 2016, Article ID 2614187, 2 pages, 2016.

[9] F. Mirzazadeh, F. Berenji, M. Amini, M. Salehi, A. Shamsian, and A. Fata, "Lophomonas blattarum in asthmatic patients and control group," Journal of Research in Medical and Dental Science, vol. 5, pp. 1-5, 2017.

[10] O. Jorjani, A. Bahlkeh, F. Koohsar, B. Talebi, and A. Bagheri, "Chronic respiratory allergy caused by Lophomonas blattarum: a case report," Medical Laboratory Journal, vol. 12, no. 2 , pp. 44-46, 2018.

[11] Y. B. Bakis, M. K. Balc1, M. K. Balci, and M. C. Bektas, "A rare reproduction in paranasal sinuses; Lophomonas blattarum," European Journal of Rhinology and Allergy, vol. 2, no. 3, pp. 89-91, 2019.

[12] C. Yazir, S. Verma, R. S. Negi, V. Kumar, S. Gupta, and V. Sharma, "Lophomonas blattarum co-infection in a patient with multidrug-resistant tuberculosis," The International Journal of Tuberculosis and Lung Disease, vol. 21, no. 10, pp. 1185-1187, 2017.

[13] R. Tyagi, K. Anand, K. Teple, and R. Negi, "Lophomonas blattarum infection in immunocompetent patient," Lung India: Official organ of Indian Chest Society, vol. 33, no. 6, p. 667, 2016.

[14] O. Zorbozan, A. Uysal, F. Bacakoğlu, N. Turgay, and S. Töz, "Lophomonas blattarum associated broncho-pulmonary infection after immunotherapy: a case report and a smart-phone based video of trophozoite/immunoterapi sonrasinda Lophomonas blattarum ile iliskili bronkopulmoner enfeksiyon: bir olgu sunumu ve trofozoitin akilli telefon kamerasi ile cekilmis videosu," Turkish Journal of Parasitology, vol. 43, no. 1, pp. 44-47, 2019.

[15] N. Ghafarian, E. Bakhtiari, F. Berenji, M. Nakhaei, B. Nakhaei, and F. Jamali-Behnam, "The study of Lophomonas blattarum infection in children with respiratory symptoms: a descriptive 
clinical study in north east of Iran," International Journal of Pediatrics, vol. 6, no. 6, pp. 7797-7802, 2018.

[16] J. Liu, S. Li, H. Li, Y. Fan, H. Yang, and H. Xu, "Bronchopulmonary disease caused by flagellated protozoa infection in 15 Chinese children," The Pediatric Infectious Disease Journal, vol. 36, no. 4, pp. 392-397, 2017.

[17] R. Sobarzo, G. Vargas, M. Pinto, and A. M. Tejada, "Detección de lophomonas blattarum en muestras de esputo teñidas con azul de metileno de individuos adultos de un área urbana de la provincia de chiriquí," Tecnociencia, vol. 22, no. 1, pp. 5-15, 2020.

[18] H. Beams and S. S. Sekhon, "Further studies on the fine structure of Lophomonas blattarum with special reference to the so-called calyx, axial filament, and parabasal body," Journal of Ultrastructure Research, vol. 26, no. 3-4, pp. 296315, 1969.

[19] R. Martinez-Giron and H. C. Van Woerden, "Lophomonas blattarum and bronchopulmonary disease," Journal of Medical Microbiology, vol. 62, no. 11, pp. 1641-1648, 2013.

[20] X. Zhang, L. Xu, L. Wang, S. Liu, J. Li, and X. Wang, "Bronchopulmonary infection with Lophomonas blattarum: a case report and literature review," Journal of International Medical Research, vol. 39, no. 3, pp. 944-949, 2011.

[21] M. Talebian, F. Berenji, M. Amini, S. J. Sayedi, A. Shamsian, and M. Afzalaghaee, "A study about clinical symptoms and laboratory signs of adult and pediatric patients with Lophomonas blattarum," Journal of Research in Medical and Dental Science, vol. 6, no. 1, pp. 312-317, 2018.

[22] Q. He, X. Chen, B. Lin, L. Qu, J. Wu, and J. Chen, "Late onset pulmonary Lophomonas blattarum infection in renal transplantation: a report of two cases," Internal Medicine, vol. 50, no. 9, pp. 1039-1043, 2011.

[23] G. Splendiani, S. Cipriani, G. Tisone, B. Iorio, S. Condo, and A. Vega, Eds., Transplantation Proceedings, Elsevier, Amsterdam, Netherlands, 2005.

[24] P. L. Brand, E. Baraldi, H. Bisgaard, A. Boner, J. CastroRodriguez, and A. Custovic, "Definition, assessment and treatment of wheezing disorders in preschool children: an evidence-based approach," European Respiratory Journal, vol. 32, no. 4, pp. 1096-1110, 2008.

[25] Y. Shi, L. Li, Y. Liao, X. Li, X. Huang, and J. Liu, "Diagnosis and treatment of Lophomonas blattarum infection in 26 patients with bacterial pneumonia," Zhongguo Ji Sheng Chong Xue Yu Ji Sheng Chong Bing Za Zhi= Chinese Journal of Parasitology \& Parasitic Diseases, vol. 25, no. 5, pp. 430-431, 2007.

[26] N. G. Saldaña, F. J. O. Mendoza, F. R Larrauri, D. M. G. Trujillo, E. V. Montoya, and E. A. De La Garza, "Bronchopulmonary infection by Lophomonas blattarum in a pediatric patient after hematopoietic progenitor cell transplantation: first report in Mexico," Journal of Thoracic Disease, vol. 9, no. 10, p. E899, 2017.

[27] X. Rao, Q. Liao, T. Pan, S. Li, X. Zhang, and S. Zhu, "Retrospect and prospect of Lophomonas blattarum infections and lophomoniasis reported in China," Open Access Library Journal, vol. 1, no. 9, p. 1, 2014. 